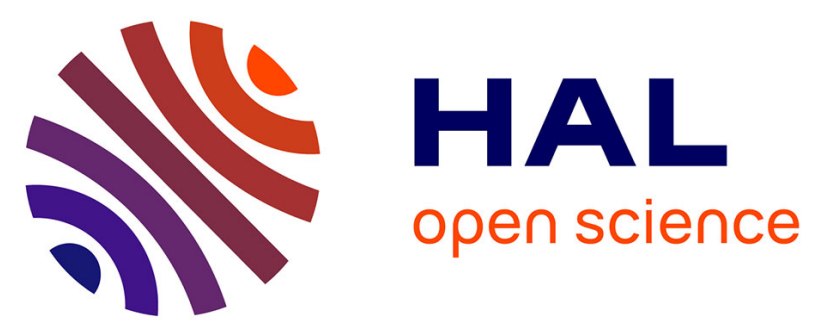

\title{
Dielectric engineering of nanostructured layers preventing electrostatic charging in thin dielectrics
}

Kremena Makasheva, Christina Villeneuve-Faure, Caroline Bonafos, Christian Laurent, Alessandro Pugliara, Bernard Despax, Laurent Boudou, G. Teyssedre

\section{- To cite this version:}

Kremena Makasheva, Christina Villeneuve-Faure, Caroline Bonafos, Christian Laurent, Alessandro Pugliara, et al.. Dielectric engineering of nanostructured layers preventing electrostatic charging in thin dielectrics. Nanotechnology Materials and Devices Conference (NMDC), 2015 IEEE, Sep 2015, Anchorage, United States. 10.1109/NMDC.2015.7439236 . hal-01763535

\section{HAL Id: hal-01763535 \\ https://hal.science/hal-01763535}

Submitted on 11 Dec 2020

HAL is a multi-disciplinary open access archive for the deposit and dissemination of scientific research documents, whether they are published or not. The documents may come from teaching and research institutions in France or abroad, or from public or private research centers.
L'archive ouverte pluridisciplinaire $\mathbf{H A L}$, est destinée au dépôt et à la diffusion de documents scientifiques de niveau recherche, publiés ou non, émanant des établissements d'enseignement et de recherche français ou étrangers, des laboratoires publics ou privés. 


\title{
Dielectric engineering of nanostructured layers preventing electrostatic charging in thin dielectrics
}

\author{
Kremena Makasheva, Member, IEEE, Christina Villeneuve-Faure, Caroline Bonafos, \\ Christian Laurent, Fellow, IEEE, Alessandro Pugliara, Bernard Despax, Laurent Boudou and \\ Gilbert Teyssedre, Member, IEEE
}

\begin{abstract}
${ }^{1 \square}$ Abstract-New dielectric-engineering concept is developed intending a net improvement of the performance of dielectric layers under electrical stress. Instead of synthesis of new dielectric materials a new class of dielectric layers that gain their performance from design rather than from composition is established. Two kinds of nanostructured dielectric layers are presented here: (i) silicon oxynitride layers $\left(\mathrm{SiO}_{\mathrm{x}} \mathrm{N}_{\mathrm{y}}: \mathrm{H}\right)$ with gradual variation of their properties (discrete or continuous), and (ii) $\mathrm{SiO}_{2}$ layers with tailored interfaces; a single layer of silver nanoparticles (AgNPs) is embedded in the vicinity of the dielectric free surface. Modulation of the conductive properties of the nanostructured layers over 7 orders of magnitude is achieved. The nanostructured layers exhibit much shorter charge retention times and appear promising candidates for general applications where surface charging of dielectrics must be avoided, in particular for implementation in RF MEMS capacitive switches with electrostatic actuation.
\end{abstract}

\section{Topic-MEMS/NEMS}

Index Terms/Keywords - silver nanoparticles, silicon nanoparticles, nanostructured dielectric layers, plasma processes

\section{INTRODUCTION}

THE electrostatic charging of thin dielectric layers represents an intensive field of scientific research, yet requiring a comprehensive study. The charge injection in dielectrics is at the origin of space charge formation $[1,2]$ leading in some cases to unexpected behaviour of the dielectric layers under electrical stress. Although the electrostatic charging of thin dielectric layers lays down the principle of operation of various technological devices, like non-volatile memories [3, 4], it is considered as the main cause of electrostatic sticking in MicroElectroMechanical Systems (MEMS) [5-7]. Indeed, the dielectric charging in RF MEMS switches is at the origin of failure and low reliability of capacitive switches with electrostatic actuation. Charge trapping on the surface and in the volume of the dielectric layer leads to a significant increase of the surface potential and to a modification of the values of applied voltage for switch actuation in a way that

1 This work was financially supported by the Agence Nationale de la Recherche in France, project ANR-InTail under contract ANR-AA-PBLI-II2011. The authors acknowledge financial support from the French CNRS and CEA METSA network for the TEM observations, project METSA 11B14.

K. Makasheva, C. Villeneuve-Faure, C. Laurent, A. Pugliara, B. Despax, L. Boudou and G. Teyssedre are with LAPLACE laboratory, Université de Toulouse; CNRS, UPS, INPT; 118 route de Narbonne, F-31062 Toulouse, France (e-mail: kremena.makasheva@laplace.univ-tlse.fr,). C. Bonafos and A. Pugliara are with Groupe Nanomat-CEMES-CNRS, Université de Toulouse, 29 Jeanne Marvig, BP 94347, F-31055 Toulouse, France. after certain number of events the switch is out of control.

This work presents an experimental study on the synthesis, structural and electrical characterization of nanostructured layers preventing the electrostatic charging in thin dielectrics. Instead of synthesis of new materials, a new class of dielectric layers that gain their performance from design rather than from composition is established. Two kinds of nanostructured layers are presented: (i) silicon oxynitride layers $\left(\mathrm{SiO}_{\mathrm{x}} \mathrm{N}_{\mathrm{y}}: \mathrm{H}\right)$ with gradual variation of their properties (discrete or continuous), and (ii) silica layers $\left(\mathrm{SiO}_{2}\right)$ with tailored interfaces; a single layer of silver nanoparticles (AgNPs) is embedded at the vicinity of the dielectric free surface.

\section{EXPERIMENTAL PART}

The nanostructured dielectric layers were deposited in a Plasma Enhanced Chemical Vapor Deposition (PECVD) process, fully compatible with microelectronic technology. Capacitively coupled radio-frequency (RF) discharges operating at $13.56 \mathrm{MHz}$ and low gas pressure (tens of $\mathrm{Pa}$ ) were used for deposition $[8,9]$. The nanostructured layers with gradual properties (discrete or continuous) are composed of levels of amorphous silicon oxynitride layers $\left(a-\mathrm{SiO}_{\mathrm{x}} \mathrm{N}_{\mathrm{y}}: \mathrm{H}\right.$, $\mathrm{x}<2, \quad \mathrm{y}<1)$ with different $\mathrm{Si}$ concentration. The plasma precursor ratio $\gamma=\left[\mathrm{N}_{2} \mathrm{O}\right] /\left[\mathrm{SiH}_{4}\right]$ allows adjusting the Sicontent in the film. The dielectric layer with $\gamma=100$ exhibits properties close to a thermal $\mathrm{SiO}_{2}$ layer. The lower the $\gamma$-value, the richer in $\mathrm{Si}$ the dielectric layer is. To realize the nanostructured dielectric layer with tailored interfaces a single layer of AgNPs is deposited on thermally grown $\mathrm{SiO}_{2}$ layer and covered by dielectric layers with different thicknesses of either plasma organosilicon deposits $\left(\mathrm{SiO}_{\mathrm{x}} \mathrm{C}_{\mathrm{y}}: \mathrm{H}\right)$ or plasma silica $\left(\mathrm{SiO}_{2}\right)$ layers.

The nanocomposite layers were structurally characterized by Transmission Electron Microscopy (TEM) in crosssectional (XS-TEM) and plan view (PV-TEM). The observations were performed using a field emission TEM, FEI Tecnai ${ }^{\text {TM }}$ F20 microscope operating at $200 \mathrm{kV}$, equipped with a spherical aberration corrector and the Gatan Imaging Filter (GIF) TRIDIEM. The Fourier Transform Infrared (FTIR) spectra were acquired with a Brucker Vertex 70 spectrometer in the range $400-4000 \mathrm{~cm}^{-1}$. Thicknesses of the nanostructures were determined by spectroscopic ellipsometry using a SOPRA GES-5 ellipsometer. The nanostructured layers were electrically tested under electrical stress and environmental conditions typical for RF MEMS switches. Charge injection and decay dynamics were probed by Kelvin Force Microscopy (KFM) with Multimode 8 Bruker apparatus according to the experimental protocol described in [10]. 


\section{RESULTS AND DISCUSSION}

\section{A. Silicon oxynitride layers with gradual properties}

Dielectric engineering, as performed in this work, allows exploring a large band of operating conditions of the nanostructured layers. To prevent electrostatic charging effects the nanostructures are engineered with a high resistivity layer $(\gamma=100$ or 25$)$ on bottom to assure good isolation. In the following levels the conductivity is increased by increasing the Si-content $(\gamma=10)$ to finish with a top level having further increased conductivity $(\gamma=5$ or 2$)$. A nanostructure $(\gamma=25 \rightarrow 10 \rightarrow 5 \rightarrow 2)$ with continuous variation of the properties is shown in Fig. 1.
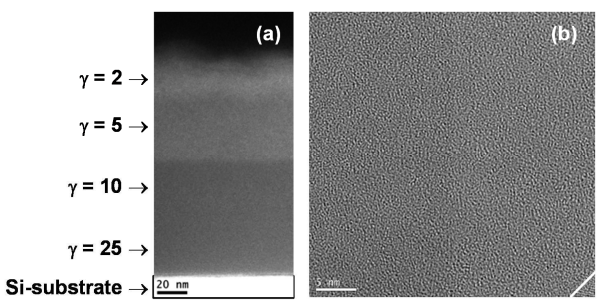

Fig. 1. TEM images of $\mathrm{SiO}_{\mathrm{x}} \mathrm{N}_{\mathrm{y}}: \mathrm{H}$ nanostructured layer with continuous variation of its properties $(\gamma=25 \rightarrow 10 \rightarrow 5 \rightarrow 2)$ : (a) Energy Filtered TEM image in XS-view, and (b) High Resolution TEM image in XS-view.

The evolution with charging time of the integrated intensity of potential profiles for bias voltage of $25 \mathrm{~V}$ as performed in the KFM study is shown in Fig. 2a for mono-layers with different $\gamma$-values and for two nanostructured layers with continuous levels $\gamma=100 \rightarrow 25 \rightarrow 10 \rightarrow 5$ and $\gamma=100$, $25 \rightarrow 10 \rightarrow 5 \rightarrow 2$, called grad5 and grad2. The small integrated intensity $\left(I_{s}\right)$ for the highly insulating layers $(\gamma=100$ and 25$)$ is related to low density of injected charges. The Si-rich layers $(\gamma=5$ and 2$)$ also exhibit small integrated intensity with saturation effect due to increased charge transport in depth of the layer, as well as transversally (the FWHM is doubled). The intermediate layer $(\gamma=10)$ presents very strong increase of the integrated intensity and fast surface charge diffusion. The two nanostructured layers combine the properties of the constituent layers and behave like insulating layers in terms of charge saturation effect, and like Si-rich layers in terms of charge transport in the volume, however governed by the properties of the intermediate layers with strong surface diffusion.
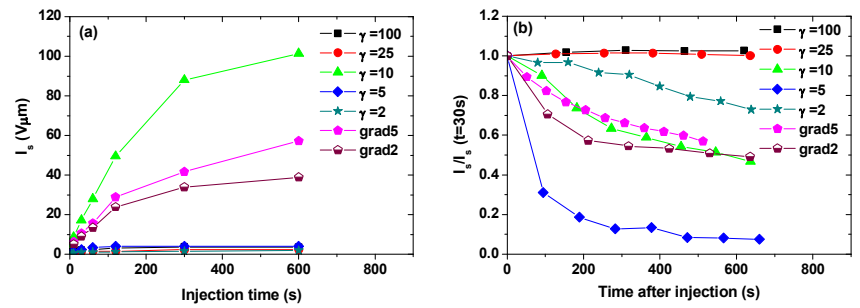

Fig. 2. Evolution of (a) the integrated intensity, $\mathrm{I}_{\mathrm{s}}$ for $25 \mathrm{~V}$ bias on the AFM tip, and (b) the $I_{s}$ normalized to its value at $30 \mathrm{~s}$ after injection (technological time to start measurements). Charge injection for 5 min at $25 \mathrm{~V}$.

The charge decay mechanisms are also classified according to the layer composition (Fig. 2b). The nanostructured layers follow the decay of intermediate layer revealing simultaneous action of surface and volume charge transport, however modulated by the presence of other levels in the nanostructure.

Combined effect of increased dielectric constant, by increasing the Si-content in the layer, with fast charge decay in the nanostructured layers qualifies them as appropriate for application in capacitive RF MEMS switches.

\section{B. Silica layers with tailored interfaces}

Tailoring the properties of a $\mathrm{SiO}_{2}$ layer is achieved by embedding a single layer of AgNPs (below the percolation threshold) at the vicinity of the dielectric free surface (Fig. 3). The AgNPs are thought to play the role of deep trapping centers thereby stabilizing the charge injection due to the field reduction at the electrode when the AgNPs are charged.
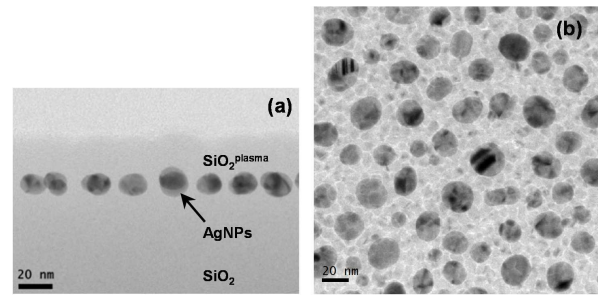

Fig. 3. Bright field TEM images of $\mathrm{SiO}_{2}$ layers with tailored interfaces: (a) XS-TEM image and (b) PV-TEM image.

Two types of plasma deposits are tested as cover layers: silica $\left(\mathrm{SiO}_{2}\right)$ and organosilicon $\left(\mathrm{SiO}_{\mathrm{x}} \mathrm{C}_{\mathrm{y}}: \mathrm{H}\right) . \mathrm{KFM}$ measurements of the potential profile induced by charge injection reveal strong lateral charge spreading for the nanostructure with AgNPs covered by $\mathrm{SiO}_{\mathrm{x}} \mathrm{C}_{\mathrm{y}}: \mathrm{H}$ layer.

\section{CONCLUSION}

Dielectric engineering of thin dielectric layers is applied to establish a new class of nanostructures preventing electrostatic charging. The obtained results show that strong gradual variation of the conductive properties across the nanostructured dielectrics provides efficient charge transport in depth of the structure and reduces the electric field at the surface, decreasing in that way the density of injected charges. The presented nanostructured layers appear quite promising for application in RF MEMS capacitive switches.

\section{REFERENCES}

[1] C. Laurent, G. Teyssedre, S. Le Roy, and F. Baudoin, IEEE Trans. Dielectr. Electr. Insul., vol. 20, pp. 357-381, 2013.

[2] T. Tanaka, IEEE Trans. Dielectr. Electr. Insul., vol. 12, pp. 914-928, 2005.

[3] P. Normand et al., Microelectron. Eng., vol. 67-68, pp. 629-634, 2003.

[4] S. Perret-Tran-Van, K. Makasheva, B. Despax, C. Bonafos, P. E. Coulon, and V. Paillard, Nanotechnology, vol. 21, p. 285605, 2010.

[5] G. M. Rebeiz, RF MEMS Theory, Design, and Technology, Hoboken, New Jersy: John Wiley \& Sons, Inc., 2003.

[6] W. M. Zhang, G. Meng, and D. Chen Sensors, vol. 7, pp. 760-796, 2007.

[7] N. Tavassolian, M. Koutsoureli, E. Papandreou, G. Papaioannou, B. Lacroix, Z. Liu, J. Papapolymerou, IEEE Transactions on Microwave Theory and Techniques, vol. 57, pp. 3518-3524, 2009.

[8] K. Makasheva, B. Despax, L. Boudou, and G. Teyssedre, IEEE Trans. Dielectr. Electr. Insul., vol. 19, pp. 1195-1202, 2012.

[9] A. Pugliara, C. Bonafos, R. Carles, B. Despax, and K. Makasheva, Material Research Express, vol. 2, p. 065005, 2015.

[10] C. Villeneuve-Faure, K. Makasheva, C. Bonafos, B. Despax, L. Boudou, P. Pons, and G. Teyssedre, J. Appl. Phys., vol. 113, p. 204102, 2013. 